\title{
A REDENÇÃO DO ÉDIPO
}

\author{
LA REDENCIÓN DEL ÉDIPO
}

THE REDEMPTION OF OEDIPUS

\author{
Marcio Farias ${ }^{1}$ \\ ${ }^{1}$ Pontifícia Universidade Católica de São Paulo, SP, Brasil
}

\section{Resenha de}

Kon, N. M., Silva, M. Lúcia, \& Abud, C. C. (Orgs.). (2017). O racismo e o negro no Brasil: questões para a psicanálise. São Paulo: Perspectiva.

A obra A Redenção de Cam (1895), do pintor galego Modesto Brocos, se tornou uma das mais emblemáticas pinturas na história da arte brasileira. O título recupera um controverso momento da escravidão moderna, quando da justificação da escravização de africanos pela leitura da passagem bíblica sobre Cam, que ao ver seu pai bêbado e despido, riu-se e contou a seus outros irmãos, Sem e Jafé. Noé, ao saber da história amaldiçoou o filho, lançando sua indignação ao neto, Canaã: este trabalharia eternamente aos descendentes de seus tios. No século XVI, leu-se que os pôsteres de Canaã eram os africanos. Na obra em questão, a cena retratada pela pintura de Brocos destaca três gerações distintas. No campo esquerdo, vê-se uma mulher negra idosa, com as mãos erguidas para o céu, com alusão de estar agradecendo. No centro, uma jovem mulher negra mestiça, que tem sobre os joelhos o filho mestiço claro. A direita está um homem branco que observa satisfeito aquele que provavelmente é seu filho. Nesse sentido, o artista ao fazer esta alusão, pressupõe uma superação deste momento dramático da história de um território que posteriormente se tornou o país Brasil.

É no mesmo contexto da obra de Brocos que a psicanálise ingressa no país, tendo dois vetores: um clínico, absorvido por médicos e psiquiatras, alguns ligados ao pensamento racialista; outro, cultural, este ligado a intelectuais e artistas de vanguarda. Assim, entre os primeiros esboços das últimas décadas do século XIX até 1930, a ciência do inconsciente ganhou forma e variou nos seus conteúdos. Era preciso alguma argamassa que juntasse simbolicamente a massa desigual social e economicamente, diversa geográfica e culturalmente. A comunidade imaginada Brasil, com suas tradições a serem inventadas, teve também na psicanálise uma sustentação para o começo da consolidação da avenida que escoaria em um futuro ordeiro e progressista.

Participante ativa do elo que cria o discurso de nação, a psicanálise brasileira seguiu seu rumo clínico e cultural. Na clínica desenvolveu-se no compasso das grandes escolas europeias e estadunidenses, tornando-se uma sucursal dessas matrizes. A demanda explica a escolha, um público de classe média branca que se projetava enquanto europeu nos trópicos. Na moderna sociedade brasileira, de harmonia cultural das raças, mas que se ergueu enquanto sociedade de classes dinâmica para brancos e como sociedade de estamentos para não brancos, o específico tido como universal deu conta do atendimento clínico. Na cultura, sempre foi tema para as vanguardas, vide o Tropicalismo, mas sem alcançar o conteúdo recalcado do trauma brasileiro. 
Eis que recentemente surge um livro que caminha no sentido de ser a redenção do Édipo em terras tupiniquins. O racismo e o negro no Brasil: questões para a psicanálise (2017) organizado por Noemi Moritz Kon, Maria Lúcia da Silva e Cristiane Curi Abud, lançado pela editora Perspectiva. Neste ponto, é importante frisar que os termos "redenção do édipo" utilizado neste texto se refere à uma figura de linguagem, cujo objetivo é retórico e não analítico.

A origem do movimento que possibilitou esta publicação se deu num curso de formação em psicanálise do importante Instituto Sedes Sapientae. Na ocasião, um debate levado a cabo em sala de aula gerou um seminário e dali algumas falas transcritas e outros textos de autores convidados compõe este importante tomo. Organizado em 4 partes, o livro tem no total 15 capítulos que buscam meandrar pelos labirintos do racismo e seus desdobramentos. O mérito do livro está na reunião de um conjunto amplo de possibilidades e debates críticos acerca do enfrentamento ao racismo no Brasil. Em linhas gerais, temos dois eixos interpretativos postos: debates consagrados e novos enfoques sobre o racismo a partir e para a psicanálise.

Agora, ao contrário do cenário do início do século XX, no contexto contemporâneo, o livro abalizado na psicanálise se insere diante de uma ampla fortuna crítica sobre o racismo no Brasil sob as mais diversas perspectivas e produzido pelas mais variadas áreas do saber. A própria psicologia e, mais especificamente, a psicanálise dispõe de um cabedal de produção significativo sobre o tema. Ainda assim, os desafios e agenda de pesquisa e atuação carecem de aprofundamento, possibilitado pelo bom debate, confronto, discussão e divergências, fundamentais para o avanço de qualquer área sobre qualquer assunto e, neste caso, em especial, um tema de tamanha importância para a nação.

Em sendo uma coletânea, entende-se como pertinente apresentar alguns pontos centrais da obra, ratificando sua importância, seus pontos críticos e temas controversos presentes nos artigos. Assim sendo, no eixo de debates consagrados, há reunião de nomes conhecidos e de prestígio no campo dos estudos sobre relações raciais no Brasil, que trazem para este livro aspectos de suas contribuições teóricas. Nesse sentido, o antropólogo Kabenguele Munanga, escreve sobre o complexo e ambíguo racismo à brasileira, que absorve a afirmação do racismo e a sua negação, na medida em que, segundo o autor, o processo histórico do Brasil conformou uma ideologia que enfatiza a mestiçagem como tipo ideal de nação, ainda que o mestiço não se beneficie disso. A historiadora e antropóloga Lilia Moritz Schwartz, por sua vez, recupera um de seus textos clássicos sobre o tema, quando, influenciada pelo cientista politico Benedict Anderson, propõe a discussão sobre o processo de consolidação do projeto de nação no país. Sua contribuição é incontornável: raça é tema central para pensar o Brasil moderno. Já o escritor e crítico literário Cuti coloca em questão os signos "negro" e "afrodescendente" diante da evolução política do Movimento Negro e da luta antirracista no Brasil. O escritor, ao restituir a história da população negra, demonstra o quanto a palavra "negro" é a expressão de uma luta, a ressignificação de um termo e o seu realocamento diante do imperioso confronto do racismo Do contrário, afrodescendente diluí o conflito, atomiza a luta e harmoniza o encontro desigual das raças no Brasil.

Ainda no eixo de debates consagrados, os psicólogos e psicanalistas Fúlvia Rosemberg, José Moura de Gonçalves Filho, Isildinha Nogueira e Maria Lúcia da Silva tratam, a partir de seus respectivos legados teóricos, dos desafios a serem pensados pela psicanálise no Brasil. A começar por Maria Lúcia da Silva, cujo título do texto já expõe sua proposta de construção de uma agenda: "Racismo no Brasil: Questões para psicanalistas", por isso, 
o arremate de seu texto é providencial: "É preciso a inauguração de uma psicanálise brasileira comprometida com a construção de uma clínica que não recuse a realidade histórico-social de nosso país e que leve em consideração o impacto dessa história na construção das subjetividades" (Silva, 2017, p. 87).

Já a pesquisadora Fúlvia Rosemberg (in memoriam) repercute sobre os desafios atuais da pesquisa sobre relações raciais. As conexões entre desigualdade social e racial, identidade e política não estabelecem entre si, no Brasil, uma relação de causalidade dada, segundo Rosemberg. José Moura Gonçalves Filhos, reconstitui sua discussão sobre humilhação social e se posiciona diante de uma espécie de determinação axiomática da psicanálise: $\mathrm{O}$ inconsciente tem cor? $\mathrm{O}$ inconsciente tem classe? $\mathrm{O}$ inconsciente tem raça? Ora, para Moura, se a subjetividade se constitui nas relações sociais, portanto na cultura, negligenciar essas exterioridades é ratificar um acordo tácito com uma dominação que forja o país desde o período colonial.

Ainda sobre este eixo, por parte das negativas, exceto Fúlvia Rosemberg, todos insistem na persistência da escravidão para explicar o racismo. Os estudos contemporâneos sobre relações raciais no Brasil, desde as primeiras publicações do cientista social Carlos Hasembalg colocam, ao menos, em questão essa afirmativa enquanto valor heurístico. $\mathrm{O}$ racismo enquanto ideologia se metamorfoseou conforme as novas dinâmicas das relações sociais no Brasil. O próprio mito da democracia racial é uma forma apurada de reorientação desse mecanismo de manutenção das desigualdades no país. Esta ponderação não desabona o conjunto das avaliações levadas a cabo por estes autores.

No eixo de ensaios, Maria Beatriz da Costa Vanucci escreve um texto que é seminal. Ao recuperar um dos debates mais importantes sobre cultura de Freud, o narcisismo das pequenas diferenças, aloca o preconceito racial diante desse fenômeno de estranhamento na alteridade. Além disso, reitera o convite à uma psicanálise brasileira. A única ressalva a ser mencionada é sobre a relação entre alteridade e racismo, tema pela qual já se investiu muita tinta. Immanuel Wallerstein (1983) talvez tenha sido o autor de maior envergadura a debater esse tema, ideias que por aqui foram absorvidas pelo também importante Clóvis Moura em seu livro de maturidade A dialética radical do Brasil negro (1994/2014).

Destaco ainda o texto da parte III Desdobramentos "A Questão do racismo em um Grupo Com Fotografias" que foi escrito por Cristiane Curi Abud e Luis Sigulem e apresenta uma voz discordante ao já canônico debate proposto por Isildinha Nogueira que alude à estádio do espelho lacaniano para explicar a experiência do racismo como fator constituidor das subjetividades de crianças negras no Brasil. As autoras, ao contrário dessa tese, vão propor uma mirada para a relação entre o bebê imaginado pela mãe e o bebê real, sendo a capacidade de elaboração do luto entre o ideal e o real uma possibilidade de dar um salto qualitativo na relação entre desejo e ideias, esses amparados por uma cultura que destitua o lugar de inferioridade e negatividade da população negra. Para além de uma disputa entre a escola estruturalista da psicanálise e a do laço social, o texto nos coloca diante de uma nova agenda de atuação e pesquisa, ampliando o leque de possibilidades.

Em suma, o livro é um suporte das mais vigorosas investida de psicanalistas no Brasil contemporâneo para discutir o fenômeno do racismo. Se o intento gerará bons frutos, só o tempo irá dizer. Mas uma coisa é certa, trata-se, ao menos, de uma boa tentativa de elaboração como um potencial de redimir o traumático Édipo brasileiro. 


\section{Referências}

Anderson, B. (2008). Comunidades imaginadas: reflexões sobre a origem e a difusão do nacionalismo. São Paulo: Companhia das Letras.

Hobsbawm, E. \& Ranger, T. (1984). A invenção das tradições. Rio de Janeiro: Paz e Terra.

Kon, N. M., Silva, M. L., \& Abud, C. C. (Orgs.). (2017). O racismo e o negro no Brasil: Questões para a psicanálise. São Paulo: Perspectiva.

Moura, C. (2014). Dialética radical do Brasil negro (2a ed.). São Paulo: Fundação Maurício Grabois; Anita Garibaldi. (Obra original publicado em 1994)

Wallerstein, I. (1983). Historical Capitalism with Capitalist Civilization. London: Verso.

\section{MARCIO FARIAS}

https://orcid.org/0000-0002-3942-9862

Mestre e doutorando em Psicologia Social na PUC-SP. Coordenador do Núcleo de Extensão e Rede do Museu AfroBrasil. Professor convidado do Celacc (Centro de Estudos Latino Americanos sobre Cultura e Comunicação) Eca/ USP. Membro do colegiado do Instituto Amma Psique e Negritude. Membro de Comissões de Avaliação de Ações Afirmativas em Concursos Públicos para a Fundação Carlos Chagas.

Endereço: Av. Prof. Lúcio Martins Rodrigues, 443 Prédio 9, Sala 08 - Vila Universitaria, São Paulo - SP, 05508-020

E-mail: t_mfarias@hotmail.com 